\title{
THE ANALYSIS OF HYBRID SOLAR POWERED COOLING/HEATING SYSTEM WITH THE TRAVELLING-WAVE THERMOACOUSTIC REFRIGERATOR
}

\author{
A. Ruziewicz ${ }^{1 *}$, C.M. de Blok ${ }^{2}$ and P. Owczarek ${ }^{3}$ \\ ${ }^{1}$ Faculty of Mechanical and Power Engineering, Wroclaw University of Technology, Poland. *Corresponding author's \\ e-mail: adam.ruziewicz@pwr.edu.pl \\ 2 Aster Thermoacoustics,Smeestraat 11, 8194LG Veessen, The Netherlands. \\ ${ }^{3}$ Future Energy Management, Weegschaalstraat 45, 7521CC Enschede.
}

Keywords: thermoacoustic cooling, heating and cooling systems, solar radiation, solar collectors.

\section{Introduction}

One of common applications of thermoacoustic (TA) technology is cold production in a TA device powered by any heat source. This concept, based on combination of TA-engine and TAheat pump operating on different temperature ranges, allows conversion of heat directly into cold, using an acoustic wave as an energy carrier in between. Unlike electricity generation, heat powered thermoacoustic cooler needs no moving parts by the acoustic side. The solar and waste heat recovery in range of $70-200^{\circ} \mathrm{C}$, so far, seems to be the most competitive to conventional systems (possible) TA application [1]. Reaching the satisfying efficiency by such low temperature is possible due to the idea of multistage devices. Connecting more regenerators in series enables decrease of the onset temperature, while the exergetic efficiency of $40 \%$ is still possible to achieve [2].

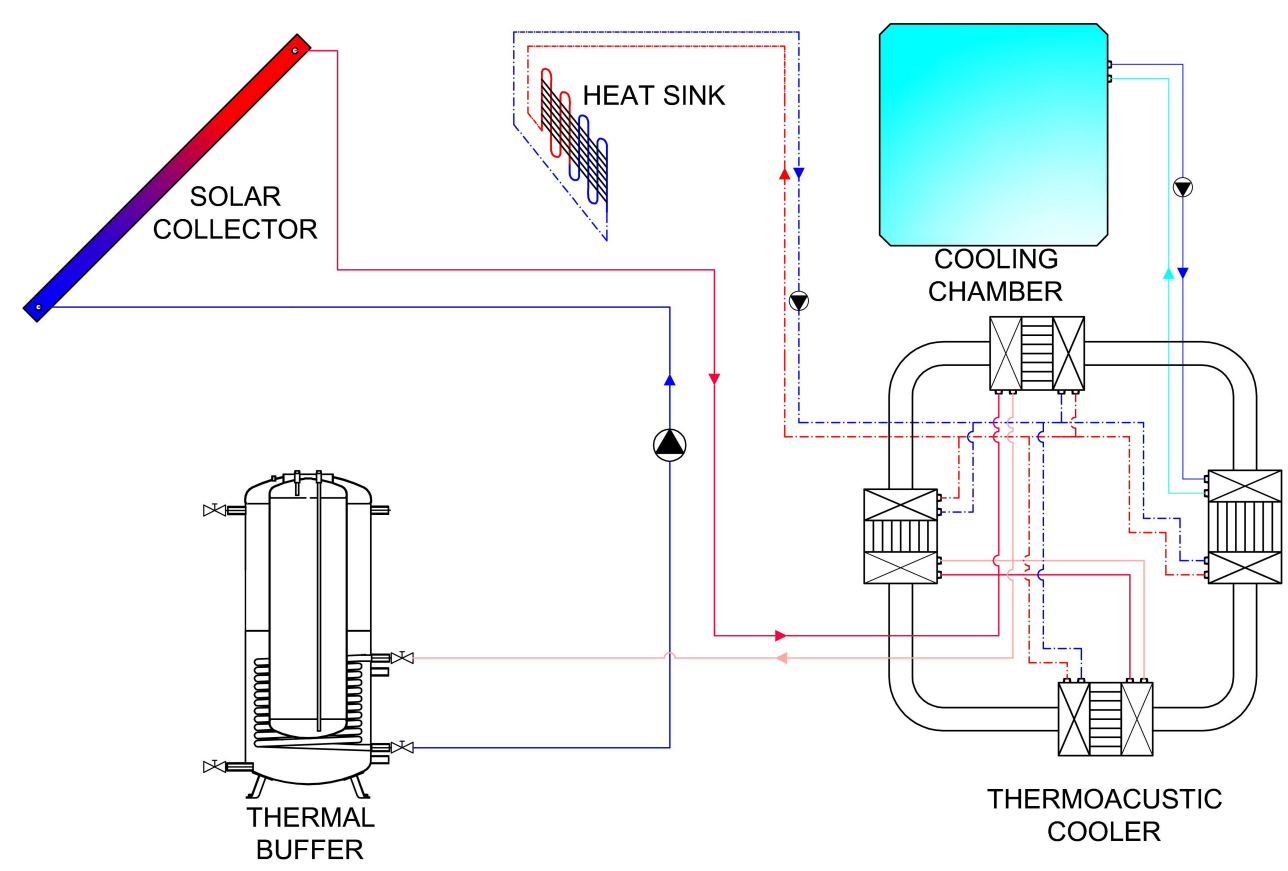

Figure 1: The scheme of the hybrid system. 
The aim of this work is to analyse the performance of the hybrid cooling and heating system driven by solar energy. The concept is to use vacuum tube solar collectors to drive the multistage thermoacoustic cooler, which takes up heat from the cooling room. Since the temperature drop on the heat exchangers of TA cooler is relatively small, the rest of the heat can be used for heating up domestic hot water (DHW). A typical sea container with tube collectors on the roof constitutes the experimental prototype. One part of the container is the cooling room, while the TA device and the DHW tank are located in the second. The simple scheme of the system is shown in the Figure 1.

Combining heating and cooling system driven by the solar power allows better matching between the demand for heat/cold and the provided energy. In the most sunny months, solar excess energy covers higher demand for cooling. In colder months the energy achieved should be enough for DHW purpose. The analysis will consider power of solar radiation and the demand for cooling power throughout the whole year. The calculated energy balance will be compared then for different months and seasons. The results for few different places (longitudes) will be provided as well, thus the viability of such hybrid system in dependence on geographical location can be evaluated.

\section{References}

[1] de Blok C.M. "Low operating temperature integral thermoacoustic devices for solar cooling and waste heat recovery". Paris, Acoustics, (2008).

[2] de Blok C.M. "Multi-stage travelling wave thermoaocustics in practise". International Congress on Sound and Vibration, Acoustics, (2012). 